\title{
Persistent export of ${ }^{231} \mathrm{~Pa}$ from the deep central Arctic Ocean over the past 35,000 years
}

\author{
Sharon S. Hoffmann ${ }^{1}$, Jerry F. McManus ${ }^{1}$, William B. Curry ${ }^{2,3}$ \& L. Susan Brown-Leger ${ }^{2}$
}

The Arctic Ocean has an important role in Earth's climate, both through surface processes ${ }^{1}$ such as sea-ice formation and transport, and through the production and export of waters at depth that contribute to the global thermohaline circulation ${ }^{2,3}$. Deciphering the deep Arctic Ocean's palaeo-oceanographic history is a crucial part of understanding its role in climatic change. Here we show that sedimentary ratios of the radionuclides thorium-230 $\left({ }^{230} \mathrm{Th}\right)$ and protactinium-231 $\left({ }^{231} \mathrm{~Pa}\right)$, which are produced in sea water and removed by particle scavenging on timescales of decades to centuries, respectively ${ }^{4}$, record consistent evidence for the export of ${ }^{231} \mathrm{~Pa}$ from the deep Arctic and may indicate continuous deepwater exchange between the Arctic and Atlantic oceans throughout the past 35,000 years. Seven well-dated box-core records provide a comprehensive overview of ${ }^{231} \mathrm{~Pa}$ and ${ }^{230} \mathrm{Th}$ burial in Arctic sediments during glacial, deglacial and interglacial conditions. Sedimentary ${ }^{231} \mathrm{~Pa} /{ }^{230} \mathrm{Th}$ ratios decrease nearly linearly with increasing water depth above the core sites, indicating efficient particle scavenging in the upper water column and greater influence of removal by lateral transport at depth. Although the measured ${ }^{230} \mathrm{Th}$ burial is in balance with its production in Arctic sea water, integrated depth profiles for all time intervals reveal a deficit in ${ }^{231} \mathrm{~Pa}$ burial that can be balanced only by lateral export in the water column. Because no enhanced sink for ${ }^{231} \mathrm{~Pa}$ has yet been found in the Arctic, our records suggest that deep-water exchange through the Fram strait may export ${ }^{231} \mathrm{~Pa}$. Such export may have continued for the past 35,000 years, suggesting a century-scale replacement time for deep waters in the Arctic Ocean since the most recent glaciation and a persistent contribution of Arctic waters to the global ocean circulation.

Waters in the Arctic are freshened by precipitation and run-off, leading to a net shallow freshwater transport into the Nordic seas ${ }^{1}$. Sea-ice production and melting freshen surface waters through salt rejection, and in some marginal settings also produce cold, saline waters that descend into the Arctic basins ${ }^{2,3}$. These dense waters travel in topographically steered deep currents and eventually transit the Fram strait, the single deep Arctic passage, into the Nordic seas, where they contribute to the production of North Atlantic Deep Water, a major component of the global thermohaline circulation ${ }^{1-3}$. Beneath the cold, fresh surface, warm, salty, Atlantic-sourced waters fill the Arctic depths above $1 \mathrm{~km}$; these waters may have deepened to dominate Arctic intermediate depths during past colder periods as a result of changes in stratification ${ }^{5}$.Such past changes in water masses may imply changing rates of ventilation and circulation.

Although variations in ratios of ${ }^{231} \mathrm{~Pa}$ and ${ }^{230} \mathrm{Th}$ in sediment can provide information about past rates of oceanographic processes including deep circulation ${ }^{6-8}$, these tracers have seldom been applied in Arctic sediments. Measurements of ${ }^{231} \mathrm{~Pa}$ and ${ }^{230} \mathrm{Th}$ in the modernday Arctic water column ${ }^{9-13}$ suggest variable particle scavenging rates of ${ }^{231} \mathrm{~Pa}$ and ${ }^{230} \mathrm{Th}$ in different parts of the basin, including relatively high scavenging rates within the Eurasian basin and in parts of the Canadian basin. The burial rate of ${ }^{230} \mathrm{Th}$ in central Arctic sediments roughly balances the water column production rate, supporting the use of ${ }^{231} \mathrm{~Pa}_{\mathrm{xs}} /{ }^{230} \mathrm{Th}_{\mathrm{xs}}$ (where the subscripts refer to 'excess' unsupported isotope activity age-corrected for radioactive decay since deposition; see Supplementary Information) as a tracer of past oceanographic processes in the Arctic ${ }^{14}$. Measured ${ }^{231} \mathrm{~Pa}_{\mathrm{xs}} /{ }^{230} \mathrm{Th}_{\mathrm{xs}}$ ratios in core-top sediments within all four Arctic sub-basins and along the AlaskaChukchi margin ${ }^{11,15}$ fall below the production ratio of 0.093, suggesting a net export of ${ }^{231} \mathrm{~Pa}$. Two records of ${ }^{231} \mathrm{~Pa}_{\mathrm{xs}}$ from the Arctic provide the first down-core evidence ${ }^{16,17}$ for past ${ }^{231} \mathrm{~Pa}$ burial, although neither is sufficiently resolved to give detailed information on patterns of ${ }^{231} \mathrm{~Pa}$ transport and deposition.

Seven box cores (Fig. 1 and Supplementary Table 1) with welldefined radiocarbon chronologies ${ }^{18,19}$ (Supplementary Table 2) from the 1994 Arctic Ocean Section cruise provide a cross-Arctic transect at depths within intermediate and deep waters (depths of $1-3.5 \mathrm{~km}$ ), which we use to examine regional and depth-related trends in ${ }^{231} \mathrm{~Pa}$ deposition and export. Deep-water residence times in these basins can vary from $\sim 150$ to $400 \mathrm{yr}$ (refs 20,21 ), similar to or longer than the residence times of dissolved ${ }^{231} \mathrm{~Pa}$ in these deep waters before scavenging by particles ${ }^{11,12}$.

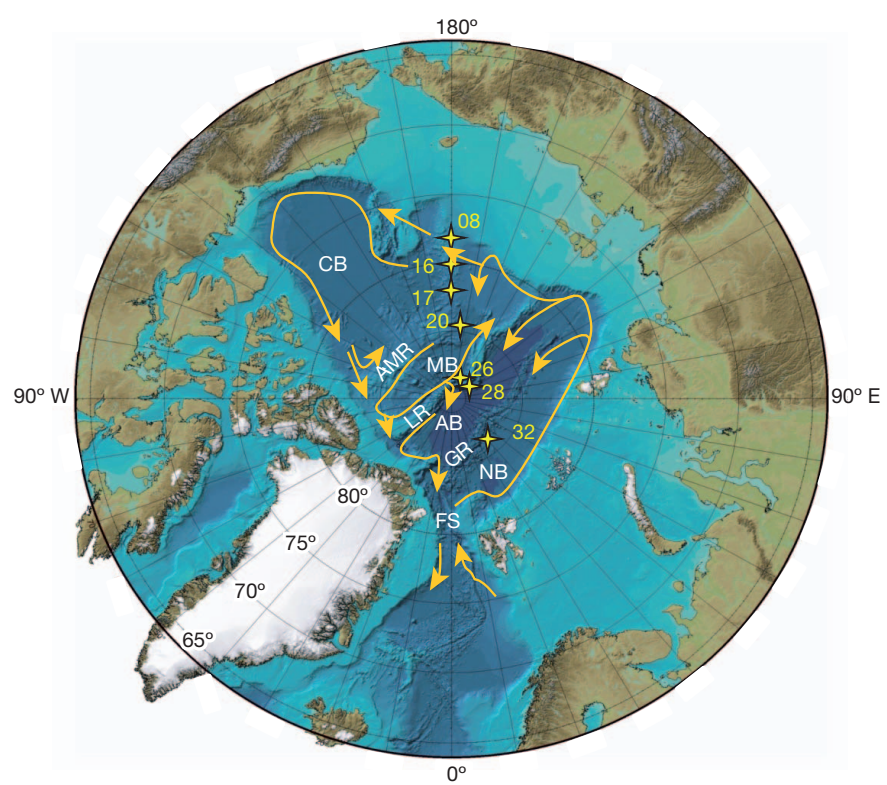

Figure 1 Locations of seven box cores in a transect across the Arctic Ocean. PL-94-AR box cores 08, 16, 17 and 20, Makarov basin, 1-3.1-km water depth. PL-94-AR box core 26, Lomonosov ridge, $1 \mathrm{~km}$; box core 28, Amundsen basin, $2 \mathrm{~km}$; box core 32 , Nansen basin, $3.5 \mathrm{~km}$. Arctic bathymetric features: CB, Canada basin; AMR, Alpha-Mendeleev ridge; MB, Makarov basin; LR, Lomonosov ridge; $\mathrm{AB}$, Amundsen basin; GR, Gakkel ridge; NB, Nansen basin; FS, Fram strait. For core coordinates and water depths, see Supplementary Table 1. Orange arrows show patterns of intermediate and deep circulation ${ }^{1-3}$. The base map used is the International Bathymetric Chart of the Arctic Ocean. 
Ratios of ${ }^{231} \mathrm{~Pa}_{\mathrm{xs}}$ to ${ }^{230} \mathrm{Th}_{\mathrm{xs}}$ (Supplementary Table 3) in our lateglacial core sections (here defined as dating from 35 to $15 \mathrm{kyr}$ ago, a period that ended with the start of North Atlantic Bølling-Allerød warming) are almost uniformly below the ${ }^{231} \mathrm{~Pa} /{ }^{230} \mathrm{Th}$ seawater production ratio of 0.093 (Fig. 2), indicating export of ${ }^{231} \mathrm{~Pa}$ from all studied sites. The lowest ratios are seen in the deepest parts of box cores 16 and 17, which are more than $35 \mathrm{kyr}$ old; these samples have large uncertainties in their modelled ages, and the low ratios in these oldest sediments may reflect under-correction for radioactive decay since deposition. There is an increase in ${ }^{231} \mathrm{~Pa}_{\mathrm{xs}} /{ }^{230} \mathrm{Th}_{\mathrm{xs}}$ at the deglaciation (here defined as 15-10 kyr ago) in five cores. In the deepest, box core 32, deglacial ratios remain low; in box core 26, at 1-km depth atop the Lomonosov ridge, ratios increase to the value of the seawater production ratio before $16.5 \mathrm{kyr}$ ago. The ${ }^{231} \mathrm{~Pa}_{\mathrm{xs}} /{ }^{230} \mathrm{Th}_{\mathrm{xs}}$ ratios reach the production ratio, indicating no local export of ${ }^{231} \mathrm{~Pa}$, in the deglacial intervals in the two other shallowest cores (box cores 08 and 16, at depths of $1-1.6 \mathrm{~km}$ ) and remain at the production ratio through the Holocene epoch in box cores 08, 16 and 26.

Holocene ratios in intermediate-depth cores vary between nearproduction-ratio levels similar to those in shallower cores and low ratios similar to those in deeper cores. Box core 17, at a depth of $2.2 \mathrm{~km}$ in the Makarov basin, and box core 28, at a depth of $2 \mathrm{~km}$ in the Amundsen basin, show synchronous millennial-scale variability in the deglacial and the early Holocene, with the highest peaks in ${ }^{231} \mathrm{~Pa}_{\mathrm{xs}}{ }^{230} \mathrm{Th}_{\mathrm{xs}}$ occurring $\sim 11 \mathrm{kyr}$ ago, followed by peaks $\sim 7.5 \mathrm{kyr}$ ago (Fig. 2). Surface-driven records such as vertical particle flux (Supplementary Fig. 1 and Supplementary Table 3) do not follow these ${ }^{231} \mathrm{~Pa}_{\mathrm{xs}}{ }^{230} \mathrm{Th}_{\mathrm{xs}}$ variations, and differ between basins, suggesting that ${ }^{231} \mathrm{~Pa}_{\mathrm{xs}}{ }^{230} \mathrm{Th}_{\mathrm{xs}}$ is more likely to be controlled by processes at depth such as ventilation and deep advection. The Arctic boundary current splits at the Lomonosov ridge, sending flows into the Amundsen basin and along the slope into the Makarov basin ${ }^{1}$; our sites at similar depths beneath this current in each basin may reflect its influence.

Average ${ }^{231} \mathrm{~Pa}_{\mathrm{xs}} /{ }^{230} \mathrm{Th}_{\mathrm{xs}}$ ratios for the late glacial, deglacial and Holocene show a strong linear relationship with water depth (Fig. 3). During each interval, ratios were highest in shallower $(1-1.6 \mathrm{~km})$ cores and lowest in deeper $(>3 \mathrm{~km})$ cores. The slope of this relationship is greater during the Holocene and deglacial than during the glacial, owing to greater differences in shallow ratios between these times. Although increased particle fluxes could lead to increased scavenging of ${ }^{231} \mathrm{~Pa}$ and, thus, higher ratios, our observed average ratio-depth relationship is not accompanied by any apparent depth trend in ${ }^{230}$ Th-normalized sediment mass fluxes (Supplementary Fig. 2); nor do particle fluxes seem to be a dominant control on ${ }^{231} \mathrm{~Pa}_{\mathrm{xs}}{ }^{230} \mathrm{Th}_{\mathrm{xs}}$ in individual cores (Supplementary Fig. 3).

This depth relationship, which has characterized central Arctic ${ }^{231} \mathrm{~Pa}_{\mathrm{xs}}{ }^{230} \mathrm{Th}_{\mathrm{xs}}$ over the past $35 \mathrm{kyr}$, mirrors a depth relationship seen in surface sediments of other Arctic cores above $3.5-\mathrm{km}$ water depth ${ }^{11,15-17}$ (Supplementary Fig. 4). Core-top ${ }^{231} \mathrm{~Pa}_{\mathrm{xs}}{ }^{230} \mathrm{Th}_{\mathrm{xs}}$ measurements from $3.5-4.5-\mathrm{km}$ water depth in the Eurasian basin ${ }^{11}$ show ratios higher than predicted by our depth trend, although all but one still fall below the production ratio.

The relationship between ${ }^{231} \mathrm{~Pa}_{\mathrm{xs}} /{ }^{230} \mathrm{Th}_{\mathrm{xs}}$ and water depth that we find in the Arctic Ocean echoes patterns found outside the Arctic despite major dissimilarities in oceanographic setting. It resembles that constrained by ${ }^{231} \mathrm{~Pa}_{\mathrm{xs}}{ }^{230} \mathrm{Th}_{\mathrm{xs}}$ surface sediments in other oceans including the eastern South Atlantic Ocean ${ }^{22}$, the North Atlantic Ocean $^{8}$ and the Pacific Ocean ${ }^{23}$, suggesting that this relationship may be global and related to seawater ingrowth and particle scavenging, rather than to local oceanography. The specific factors responsible for a relationship between sediment ${ }^{231} \mathrm{~Pa}_{\mathrm{xs}}{ }^{230} \mathrm{Th}_{\mathrm{xs}}$ and water depth remain unclear. Opal scavenges $\mathrm{Pa}$ more efficiently than do lithogenic or carbonate particles ${ }^{24,25}$ and has been implicated in the ratio-depth relationship elsewhere ${ }^{22}$. Opal contents of samples from our Arctic cores (Supplementary Table 4) show little variation and no clear relation either to water depth or to ${ }^{231} \mathrm{~Pa}_{\mathrm{xs}} /{ }^{230} \mathrm{Th}_{\mathrm{xs}}$ in the same samples, although this may be due to post-depositional dissolution on the sea floor. A simple reversible scavenging-mixing model $^{26}$ suggests that, owing to lower activities of ${ }^{231} \mathrm{~Pa}$ at shallower depths, less time is required for shallower waters to reach a steady state with respect to ingrowth and scavenging of ${ }^{231} \mathrm{~Pa}$. Shorter residence times of ${ }^{231} \mathrm{~Pa}$ in water bathing shallower core sites may lead to more balanced scavenging between ${ }^{231} \mathrm{~Pa}$ and ${ }^{230} \mathrm{Th}$, which typically has a short residence time in sea water.

No sink for the ${ }^{231} \mathrm{~Pa}$ exported from our study sites has yet been found in the Arctic. Boundary scavenging, that is, the preferential
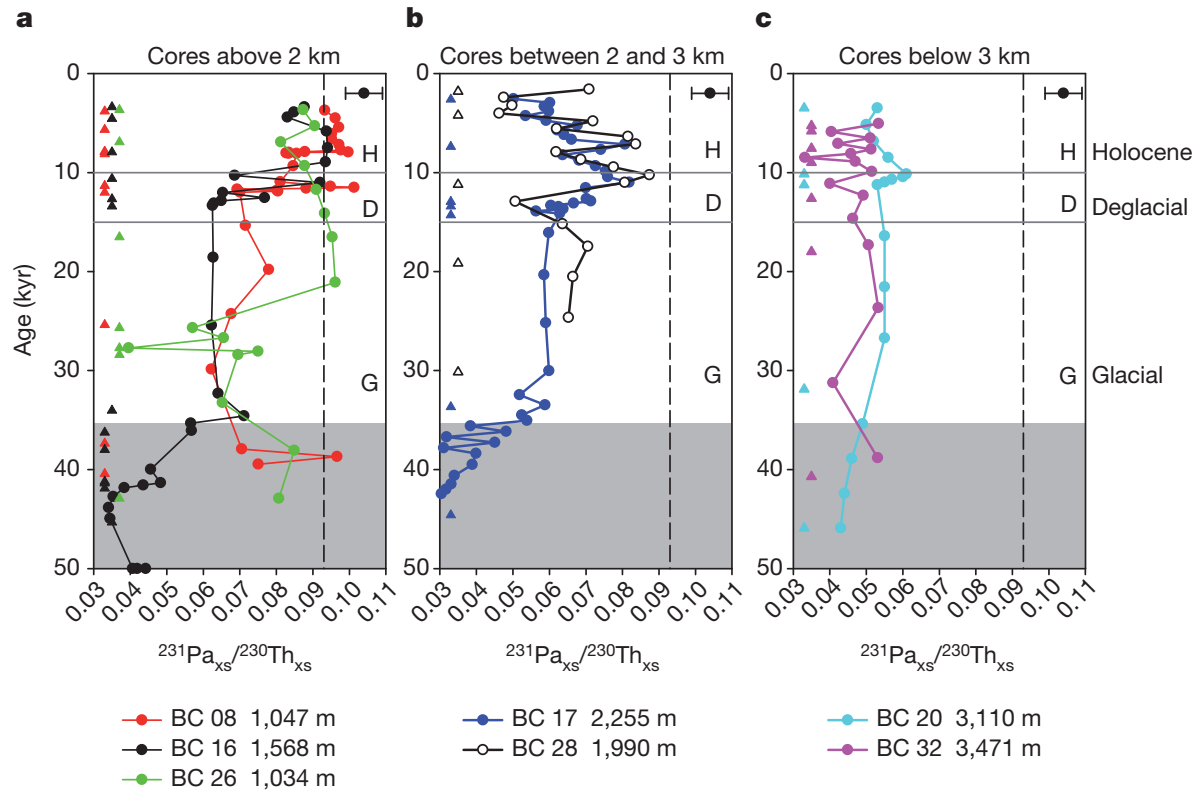

Figure $2 \mid{ }^{231} \mathrm{~Pa}_{\mathrm{xs}} /{ }^{230} \mathrm{Th}_{\mathrm{xs}}$ activity ratio records from Arctic box cores. Cores are grouped by water depth: $<2 \mathrm{~km}(\mathbf{a}), 2-3 \mathrm{~km}(\mathbf{b}),>3 \mathrm{~km}(\mathbf{c})$. Age models are based on radiocarbon dates; ratios are corrected for decay since deposition. Black points with error bars in the upper right corner of each box depict average range of $1 \sigma$ uncertainty, calculated from the standard deviation from the mean of replicate ${ }^{231} \mathrm{~Pa}_{\mathrm{xs}}{ }^{230} \mathrm{Th}_{\mathrm{xs}}$ measurements propagated with age uncertainty. Calibrated radiocarbon dates are shown at left in each plot (triangles). The dashed vertical lines show the production ratio of ${ }^{231} \mathrm{~Pa} /{ }^{230} \mathrm{Th}$ in sea water. Grey shading indicates points older than $35 \mathrm{kyr}$. BC, box core. 
a

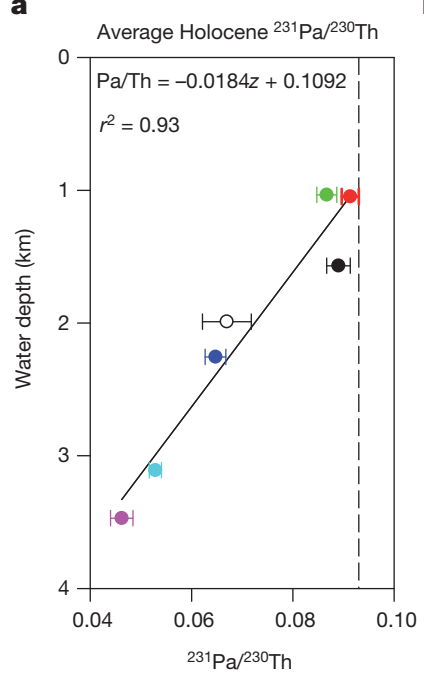

b

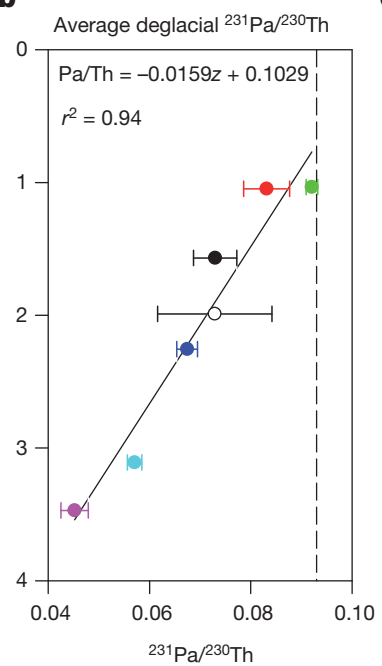

C

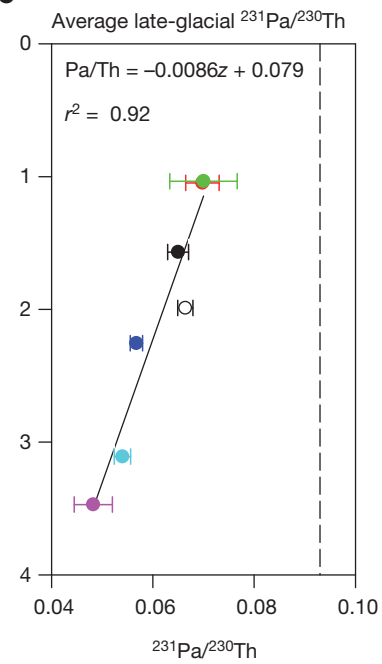

Figure $3 \mid$ Average Holocene, deglacial and late glacial ${ }^{231} \mathrm{~Pa}_{\mathrm{x}} /{ }^{230} \mathrm{Th}_{\mathrm{xs}}$ activity ratios. Ratios shown in Fig. 2 were averaged for each core over the Holocene (0-10 kyr ago; a), deglacial (10-15 kyr ago; b) and late glacial (15$35 \mathrm{kyr}$ ago; $\mathbf{c})$. The dashed lines indicate a seawater production ratio of 0.093 . Each core is coloured as in Fig. 2. Ratios decrease nearly linearly with increasing depth during all three climatic periods investigated, although the gradient of this decrease is smaller during the glacial (owing to lower ratios at shallow sites) than during the deglacial and Holocene. Error bars, 1 s.e.; $r^{2}$, coefficient of determination; $z$, water depth. removal at higher-particle-flux margins of ${ }^{231} \mathrm{~Pa}$ imported from lowerparticle-flux central basins, has been considered a likely mechanism of ${ }^{231} \mathrm{~Pa}$ removal from the Arctic water column ${ }^{11,15,27}$. Models of particlereactive metal transport in the ocean support this proposition and suggest that ${ }^{230} \mathrm{Th}$ may also be subject to boundary scavenging in the most particle-poor parts of the Arctic ${ }^{27}$. Because the existing sedimentary evidence points to local removal of ${ }^{230} \mathrm{Th}$ from sea water to sediments in the Makarov basin ${ }^{14}$, rather than lateral export of ${ }^{230} \mathrm{Th}$ to margins, boundary scavenging of ${ }^{231} \mathrm{~Pa}$ should lead to ${ }^{231} \mathrm{~Pa}_{\mathrm{xs}}{ }^{230} \mathrm{Th}_{\mathrm{xs}}$ ratios greater than the production ratio at Arctic continental slopes. At the Alaska-Chukchi continental slope in the Canada basin, in which water residence times are greater than $600 \mathrm{yr}$ (ref. 21), and near terrestrial particle sources, core-top ratios are generally less than the production ratio ${ }^{15}$ (Supplementary Information), indicating export of ${ }^{231} \mathrm{~Pa}$ produced at depth ${ }^{15}$ that is unbalanced within the Arctic proper.

The export of ${ }^{231} \mathrm{~Pa}$ out of the Arctic ${ }^{15}$ could also explain low Central Arctic ${ }^{231} \mathrm{~Pa}_{\mathrm{xs}}{ }^{230} \mathrm{Th}_{\mathrm{xs}}$ ratios. The Fram strait is the only conduit through which deep water enters and exits the Arctic, and has a sill depth of $\sim 2,500 \mathrm{~m}$. No more than $10 \%$ of ${ }^{230} \mathrm{Th}$ and roughly $39 \%$ of ${ }^{231} \mathrm{~Pa}$ produced in the Arctic Ocean is at present exported in water masses exiting southwards through the Fram strait ${ }^{14,15}$. Our results are consistent with a persistent net export of ${ }^{231} \mathrm{~Pa}$, ranging from $30 \%$ in the Holocene to $40 \%$ during the Last Glacial Maximum (Methods). Persistent ${ }^{231} \mathrm{~Pa}$ export is also consistent with continuous glacial inflow of warm Atlantic waters reaching intermediate depths during cold intervals ${ }^{5}$, which may have provided salt and mass balance for this deep outflow. Because sedimentary ${ }^{231} \mathrm{~Pa}_{\mathrm{xs}} /{ }^{230} \mathrm{Th}_{\mathrm{xs}}$ integrates overlying influences ${ }^{7}$, the inferred deepening ${ }^{5}$ of an inflow of $\operatorname{low}_{-}{ }^{231} \mathrm{~Pa}$, low- ${ }^{230} \mathrm{Th}$ water, such as that from the Atlantic, might also have an impact on the burial of ${ }^{231} \mathrm{~Pa}_{\mathrm{xs}}{ }^{230} \mathrm{Th}_{\mathrm{xs}}$, especially at shallower and intermediate depths.

Increased ${ }^{231} \mathrm{~Pa}$ export during the glacial might also be explained by even greater deep-water exchange through the Fram strait than exists today, although it more probably reflects longer residence times for dissolved Arctic ${ }^{231} \mathrm{~Pa}$ before removal by scavenging, and possibly a combination of these factors. Indeed, it seems likely that heavy perennial sea ice in the glacial Arctic led to diminished particle scavenging and, hence, an increase in dissolved ${ }^{231} \mathrm{~Pa}$ concentrations in the water column, resulting in higher ${ }^{231} \mathrm{~Pa}$ concentrations in water exiting the
Arctic. Low sedimentation rates and ${ }^{230}$ Th-normalized sediment mass fluxes (Supplementary Information), as well as reductions in metalliferous deposition ${ }^{28}$, in glacial-age Arctic sediments are consistent with this hypothesis. The $\sim 40 \%$ decrease in glacial scavenging intensity suggested by lower particle fluxes (Supplementary Information) could counter the $\sim 33 \%$ increase in ${ }^{231} \mathrm{~Pa}$ export, to result in a small net reduction $(<10 \%)$ in glacial deep-water outflow through the Fram strait, although the uncertainties associated with these estimates are too large to resolve a change of this scale.

The eventual fate of the ${ }^{231} \mathrm{~Pa}$ exported from the Arctic is presently unknown. Although ${ }^{231} \mathrm{~Pa}$ burial could occur farther south in the Nordic seas or North Atlantic, the Fram strait, with higher particle fluxes due to seasonal productivity, sea-ice transport and nearby terrigenous particle sources, could act as a likely sink for the ${ }^{231} \mathrm{~Pa}$ exported from the Arctic.

The combined observations of a balanced Arctic ${ }^{230}$ Th budget and persistent sedimentary ${ }^{231} \mathrm{~Pa}_{\mathrm{xs}}$ deficits provide constraints on the timescale of ${ }^{231} \mathrm{~Pa}$ removal from the basin. Residence times with respect to removal by scavenging for these nuclides in the water column in other oceans $\left(10-20 \mathrm{yr}\right.$ for ${ }^{230} \mathrm{Th}, 50-200 \mathrm{yr}$ for ${ }^{231} \mathrm{~Pa}$; refs 29,30$)$ indicate that the deep waters of the Arctic must be exchanged through the Fram strait on centennial timescales. Especially given the evidence for variable and possibly longer residence times in sea water for ${ }^{231} \mathrm{~Pa}$ and ${ }^{230} \mathrm{Th}$ in the Arctic ${ }^{9-13}$, any decadal-scale exchange would lead to sedimentary ${ }^{230} \mathrm{Th}_{\mathrm{xs}}$ deficits that are not observed ${ }^{14}$. Longer, millennial, timescales of exchange would not allow the widespread net sedimentary ${ }^{231} \mathrm{~Pa}_{\mathrm{xs}}$ deficit evident in core tops ${ }^{11,15-17}$ and our new down-core results. Although our evidence for greater glacial export of ${ }^{231} \mathrm{~Pa}$ is more likely to reflect diminished scavenging than enhanced deep outflow, the persistent outflow from a presumably perennially ice-covered Arctic suggests that the same sea ice and brine formation processes as today probably occurred in recurring open waters at the basin margins. The century-scale deep-water exchange is consistent with a residence time for seawater in the modern Arctic of 120-360 yr (Methods), assuming a volume of $11.455 \times 10^{6} \mathrm{~km}^{3}$ and a volume transport through the Fram strait of approximately $1-3 \mathrm{~Sv}$ (refs 3, 15). It is also consistent with estimates of the 'age' of deep waters in the Arctic basins $s^{20,21}$. Because the most important component of the Fram strait exchange for Arctic ${ }^{231} \mathrm{~Pa}$ export is the intermediate and deep outflow, the results presented here provide a proxy for reconstructing past 
dynamics of the Arctic Ocean at depth, and indicate that the outflow through the Fram strait may have persisted through the very different conditions and dramatic climate changes since the most recent glacial.

\section{METHODS SUMMARY}

Cores were sampled in $0.5-\mathrm{cm}$ slices every 1 or $0.5 \mathrm{~cm}$. Sediments were spiked with ${ }^{233} \mathrm{~Pa}$ and ${ }^{229} \mathrm{Th}$ for isotope dilution analysis and digested in $\mathrm{HClO}_{4}, \mathrm{HF}$ and $\mathrm{HNO}_{3}$. Aliquots were spiked with ${ }^{236} \mathrm{U}$ and ${ }^{229} \mathrm{Th}$ for measurement of ${ }^{238} \mathrm{U}$ and

${ }^{232} \mathrm{Th}$. Thorium and Pa fractions were purified by anion-exchange column chromatography and analysed on a Thermo-Finnegan Element 2 inductively coupled plasma mass spectrometer ${ }^{7,8}$ (ICP-MS). Measurements of ${ }^{238} \mathrm{U}$ and ${ }^{232} \mathrm{Th}$ were used to estimate supported detrital and ingrown ${ }^{231} \mathrm{~Pa}$ and ${ }^{230} \mathrm{Th}$ activity. Corrections assuming respective detrital ${ }^{238} \mathrm{U} /{ }^{232} \mathrm{Th}$ ratios of 0.5 and 0.7 were applied to each sample to calculate a range of corrected ${ }^{231} \mathrm{~Pa}_{\mathrm{xs}}$ and ${ }^{230} \mathrm{Th}_{\mathrm{xs}}$ values and their ratios ${ }^{7,8}$; these ratio values are reported in Supplementary Table 3, and average values based on these ranges are plotted in Fig. 2 and Supplementary Fig. 1. Excess values were also corrected for radioactive decay since deposition and ingrowth from authigenic $\mathrm{U}$ estimated using the same values for ${ }^{238} \mathrm{U} /{ }^{232} \mathrm{Th}$.

The uncertainty associated with ICP-MS analysis is estimated to be less than $2 \%$ for both the ${ }^{231} \mathrm{~Pa}$ and the ${ }^{230} \mathrm{Th}$ analysis. The uncertainty in our age models produces an uncertainty in age-corrected ${ }^{231} \mathrm{~Pa}_{\mathrm{xs}}{ }^{230} \mathrm{Th}_{\mathrm{xs}}$ ratios of less than $3 \%$ for age errors up to $\pm 2 \mathrm{kyr}$, incorporating uncertainties in ${ }^{14} \mathrm{C}$ analyses, reservoir correction and calendar age calibration. The average $1 \sigma$ uncertainty in ${ }^{231} \mathrm{~Pa}_{\mathrm{xs}}{ }^{230} \mathrm{Th}_{\mathrm{xs}}$, calculated from replicate analyses (Supplementary Table 5) and incorporating age uncertainty, was $\sim 8 \%$.

The data reported here, and tabulated in Supplementary Information, will be archived in the US NOAA Paleoclimatology database.

Full Methods and any associated references are available in the online version of the paper.

\section{Received 11 October 2012; accepted 4 April 2013.}

1. Rudels, B. in Encyclopedia of Ocean Sciences (eds Steele, J. H., Turekian, K. K. \& Thorpe, S. A.) 211-225 (Academic, 2009).

2. Aagaard, K., Swift, J. H. \& Carmack, E. C. Thermohaline circulation in the Arctic Mediterranean Seas. J. Geophys. Res. 90, 4833-4846 (1985).

3. Rudels, B., Friedrich, H. J.\& Quadfasel, D. The arctic circumpolar boundary current Deep Sea Res. II 46, 1023-1062 (1999).

4. Henderson, G. M. \& Anderson, R. F. The U-series toolbox for paleoceanography. Rev. Mineral. Geochem. 52, 493-531 (2003).

5. Cronin, T. M. et al. Deep Arctic Ocean warming during the last glacial cycle. Nature Geosci. 5, 631-634 (2012).

6. Yu, E.-F., Francois, R. \& Bacon, M. P. Similar rates of modern and last-glacial ocean circulation inferred from radiochemical data. Nature 379, 689-694 (1996).

7. McManus, J. F., Francois, R., Gherardi, J.-M., Keigwin, L. D. \& Brown-Leger, S. Collapse and rapid resumption of Atlantic meridional circulation linked to deglacial climate changes. Nature 428, 834-837 (2004).

8. Gherardi, J.-M. et al. Glacial-interglacial circulation changes inferred from ${ }^{231} \mathrm{~Pa} /{ }^{230} \mathrm{Th}$ sedimentary record in the North Atlantic region. Paleoceanography 24, PA2204 (2009)

9. Bacon, M. P., Huh, C.-A. \& Moore, R. M. Vertical profiles of some natural radionuclides over the Alpha Ridge, Arctic Ocean. Earth Planet. Sci. Lett. 95, 15-22 (1989).

10. Cochran, J. K., Hirschberg, D. J., Livingston, H. D., Buesseler, K. O. \& Key, R. M. Natural and anthropogenic radionuclide distributions in the Nansen Basin, Arctic Ocean: scavenging rates and circulation timescales. Deep Sea Res. // 42, 1495-1517 (1995)

11. Scholten, J. C., Rutgers van der Loeff, M. M. \& Michel, A. Distribution of ${ }^{230}$ Th and ${ }^{231} \mathrm{~Pa}$ in the water column in relation to the ventilation of the deep Arctic basins. Deep Sea Res. I/ 42, 1519-1531 (1995).
12. Edmonds, H. N. Moran, S. B, Cheng. H. \& Edwards, R. L. ${ }^{230} \mathrm{Th}$ and ${ }^{231} \mathrm{~Pa}$ in the Arctic Ocean: implications for particle fluxes and basin-scale Th/Pa fractionation. Earth Planet. Sci. Lett. 227, 155-167 (2004).

13. Trimble, S. M., Baskaran, M. \& Porcelli, D. Scavenging of thorium isotopes in the Canada Basin of the Arctic Ocean. Earth Planet. Sci. Lett. 222, 915-932 (2004).

14. Hoffmann, S. S. \& McManus, J. F. Is there a ${ }^{230}$ Th deficit in Arctic sediments? Earth Planet. Sci. Lett. 258, 516-527 (2007)

15. Moran, S. B. et al. ${ }^{231} \mathrm{~Pa}$ and ${ }^{230} \mathrm{Th}$ in surface sediments of the Arctic Ocean: implications for ${ }^{231} \mathrm{~Pa} /{ }^{230} \mathrm{Th}$ fractionation, boundary scavenging, and advective export. Earth Planet. Sci. Lett. 234, 235-248 (2005).

16. Ku, T.-L. \& Broecker, W. S. Rates of sedimentation in the Arctic Ocean. Prog. Oceanogr. 4, 95-104 (1965).

17. Not, C. \& Hillaire-Marcel, C. Time constraints from ${ }^{230} \mathrm{Th}$ and ${ }^{231} \mathrm{~Pa}$ data in late Quaternary, low sedimentation rate sequences from the Arctic Ocean: an example from the northern Mendeleev Ridge. Quat. Sci. Rev. 29, 3665-3675 (2010).

18. Poore, R. Z., Ostermann, D. R. \& McGeehin, J. Stable isotope data and AMS ${ }^{14} \mathrm{C}$ dates from Arctic Ocean Section 1994 surface sediment transect and box core samples from the Mendeleyev Ridge area. Open-File Report 99-48 (USGS, 1999).

19. Darby, D. A., Bischof, J. F. \& Jones, G. A. Radiocarbon chronology of depositional regimes in the western Arctic Ocean. Deep Sea Res. // 44, 1745-1757 (1997).

20. Schlosser, P. et al. The first trans-Arctic ${ }^{14} \mathrm{C}$ section: comparison of the mean ages of the deep waters in the Eurasian and Canadian basins of the Arctic Ocean. Nucl. Instrum. Methods 123B, 431-437 (1997).

21. Östlund, H. G., Possnert, G. \& Swift, J. H. Ventilation rate of the deep Arctic Ocean from carbon 14 data. J. Geophys. Res. 92, 3769-3777 (1987)

22. Scholten, J. C. et al. Advection and scavenging: effects on ${ }^{230} \mathrm{Th}$ and ${ }^{231} \mathrm{~Pa}$ distribution off Southwest Africa. Earth Planet. Sci. Lett. 271, 159-169 (2008).

23. Lao, Y. et al. Transport and burial rates of $\mathrm{Be}-10$ and $\mathrm{Pa}-231$ in the Pacific Ocean during the Holocene period. Earth Planet. Sci. Lett. 113, 173-189 (1992).

24. Chase, Z Anderson, R. F. Fleischer, M. Q. \& Kubik, P. W. The influence of particle composition and particle flux on scavenging of $\mathrm{Th}, \mathrm{Pa}$ and $\mathrm{Be}$ in the ocean. Earth Planet. Sci. Lett. 204, 215-229 (2002)

25. Siddall, $\mathrm{M} .{ }^{231} \mathrm{~Pa} /{ }^{230} \mathrm{Th}$ fractionation by ocean transport, biogenic particle flux and particle type. Earth Planet. Sci. Lett. 237, 135-155 (2005)

26. Luo, Y., Francois, R. \& Allen, S. E. Sediment ${ }^{231} \mathrm{~Pa} /{ }^{230} \mathrm{Th}$ as a recorder of the rate of the Atlantic meridional overturning circulation: insights from a 2-D model. Ocean Sci. Discuss 6, 382-400 (2010).

27. Roy-Barman, M. Modeling the effect of boundary scavenging on thorium and protactinum profiles in the ocean. Biogeoscience 6, 3091-3107 (2009).

28. März, C., Poulton, S. W., Brumsack, H.-J. \& Wagner, T. Manganese-rich brown layers in Arctic Ocean sediments: composition, formation mechanisms, and diagenetic overprint. Geochim. Cosmochim. Acta 75, 7668-7687 (2011).

29. Anderson, R. F., Bacon, M. P. \& Brewer, P. G. Removal of ${ }^{230} \mathrm{Th}$ and ${ }^{231} \mathrm{~Pa}$ from the open ocean. Earth Planet. Sci. Lett. 62, 7-23 (1983).

30. Yu, E.-F., Francois, R., Bacon, M. P. \& Fleer, A. P. Fluxes of ${ }^{230} \mathrm{Th}$ and ${ }^{231} \mathrm{~Pa}$ to the deep sea: implications for the interpretation of excess ${ }^{230} \mathrm{Th}$ and ${ }^{231} \mathrm{~Pa} /{ }^{230} \mathrm{Th}$ profiles in sediments. Earth Planet. Sci. Lett. 191, 219-230 (2001).

Supplementary Information is available in the online version of the paper.

Acknowledgements We thank R. Poore for sharing radiocarbon dates for box cores 28 and 32. We thank O. Marchal, R. Newton, L. F. Robinson, D. McCorkle, E. Boyle, H. Oates and M. Jackson for discussions. The manuscript was improved by the comments of A. Thomas. This work was supported in part by the Comer Science and Education Fund and by US NSF grants OCE-0402565 (J.F.M.), OCE-0550637 (J.F.M.), OCE-0902985 (J.F.M.), AGS-0936496 (J.F.M.) and ARC-0520073 (W.B.C.).

Author Contributions S.S.H. and J.F.M. designed the study with input from W.B.C. S.S.H. carried out core sampling, sediment digestions and instrumental analyses, and wrote the majority of the paper. S.B.-L. contributed to sediment digestion and analytical laboratory procedures. J.F.M. contributed to writing and revising the paper. All authors discussed the results and commented on the manuscript.

Author Information Reprints and permissions information is available at www.nature.com/reprints. The authors declare no competing financial interests. Readers are welcome to comment on the online version of the paper. Correspondence and requests for materials should be addressed to S.S.H. (ssh13@columbia.edu). 


\section{METHODS}

Sampling and isotopic analysis. Cores were sampled in $0.5-\mathrm{cm}$ slices every $1 \mathrm{~cm}$ (all box cores except 17) or $0.5 \mathrm{~cm}$ (box core 17). Sediments were spiked with ${ }^{233} \mathrm{~Pa}$ and ${ }^{229} \mathrm{Th}$ for isotope dilution analysis and digested in $\mathrm{HClO}_{4}, \mathrm{HF}$ and $\mathrm{HNO}_{3}$. Aliquots were spiked with ${ }^{236} \mathrm{U}$ and ${ }^{229} \mathrm{Th}$ for measurement of ${ }^{238} \mathrm{U}$ and ${ }^{232} \mathrm{Th}$. Thorium and $\mathrm{Pa}$ fractions were purified by anion-exchange column chromatography and analysed on a Thermo-Finnegan Element 2 ICP-MS ${ }^{31}$. Repeated measurements of ${ }^{235} \mathrm{U} /{ }^{238} \mathrm{U}$ ratios in the $\mathrm{U}$ standard solution $\mathrm{NBS} 960$ were used to correct for isotope mass fractionation during ICP-MS analysis. Measurements of ${ }^{238} \mathrm{U}$ and ${ }^{232} \mathrm{Th}$ were used to estimate supported detrital and ingrown ${ }^{231} \mathrm{~Pa}$ and ${ }^{230} \mathrm{Th}$ activity. Corrections assuming respective detrital ${ }^{238} \mathrm{U} /{ }^{232} \mathrm{Th}$ ratios of 0.5 and of 0.7 were applied to each sample to calculate a range of corrected ${ }^{231} \mathrm{~Pa}_{\mathrm{xs}}$ and ${ }^{230} \mathrm{Th}_{\mathrm{xs}}$ values and their ratios; these ratio values are reported in Supplementary Table 3. Average values based on the corrected ranges are reported in Supplementary Table 3 and plotted in Fig. 2 and Supplementary Fig. 1. Excess values were corrected for effects of both radioactive decay since deposition and authigenic ingrowth. (Published core-top excess ratios from other studies discussed in this paper have not been corrected for decay since deposition.)

The uncertainty associated with ICP-MS analysis is estimated to be less than $2 \%$ for both the ${ }^{231} \mathrm{~Pa}$ and the ${ }^{230} \mathrm{Th}$ analysis. The uncertainty in our age models produces an uncertainty in age-corrected $\left.{ }^{231} \mathrm{~Pa}_{\mathrm{xs}}\right|^{230} \mathrm{Th}_{\mathrm{xs}}$ ratios of less than $3 \%$ for age errors up to $\pm 2 \mathrm{kyr}$. The average $1 \sigma$ uncertainty in ${ }^{231} \mathrm{~Pa}_{\mathrm{xs}}{ }^{230} \mathrm{Th}_{\mathrm{xs}}$ calculated from replicate analyses was $\sim 8 \%$.

Core chronologies. We constructed age models by linear interpolation between radiocarbon-dated intervals, using both published dates ${ }^{18,19}$ and dates new to this study. Radiocarbon ages were converted to calendar years using the CALIB 5.2 program $^{32}$ and the MARINECAL 04 marine calibration data set ${ }^{33}$ for ages less than $22 \mathrm{kyr}$, and the calibration from ref. 34 for greater ages ${ }^{34}$. A local difference in reservoir age of $\Delta R=40 \mathrm{yr}$, to provide a reservoir age of $440 \mathrm{yr}$, following the studies in which a number of the dates used here were published ${ }^{18,19,35}$, plus an additional 250 -yr $\Delta R$ (refs 36-38), to account for the likely additional influence of sea ice on air-sea gas exchange, were applied to all ages.

Published radiocarbon dates were measured from samples of the polar planktonic foraminifera Neogloboquadrina pachyderma sinistral, for box cores 08,16 and $17^{18}$ (from the same subcores that we sampled for nuclide records). Published dates for box core $20^{19}$ were measured in a different subcore from that used for nuclide sampling. Although stratigraphy can vary by several centimetres between subcores of the same box core, our coarse fraction weight per cent record in box core 20 matches the published record ${ }^{19}$ quite well, suggesting little stratigraphic offset between that subcore and ours. Dates for box cores 28 and 32 (R. Poore, personal communication) were produced from the same subcores as our radionuclide records. Dates from box core 26 (this study) were measured from
N. pachyderma sinistral at the NOSAMS facility at Woods Hole Oceanographic Institution.

Additional methods. Biogenic silica contents (Supplementary Table 4) of selected samples were measured at the Lamont-Doherty Earth Observatory using standard methods ${ }^{39}$.

${ }^{230} \mathrm{Th}_{\mathrm{xs}}$-normalized sediment mass fluxes ${ }^{40}$ to the seafloor were calculated according to the equation $F=\left.\beta z\right|^{230} \mathrm{Th}_{\mathrm{xs}}$, where $\beta$ is the production rate of ${ }^{230} \mathrm{Th}$ in seawater $\left(0.0267\right.$ d.p.m. $\left.\mathrm{m}^{-3} \mathrm{kyr}^{-1}\right), z$ is the water depth of the site (in metres) and $F$ is reported in units of $\mathrm{g} \mathrm{cm}^{-2} \mathrm{kyr}^{-1}$.

Our estimates of persistent Holocene and glacial export of ${ }^{231} \mathrm{~Pa}$ from the Arctic Ocean as a whole were calculated using estimates of Arctic water volume, at 0.5-km depth increments, inferred from Arctic basin hyposometry ${ }^{41}$, and the average ${ }^{231} \mathrm{~Pa}$ export within each such water depth increment was inferred from ${ }^{231} \mathrm{~Pa}_{\mathrm{xs}}{ }^{230} \mathrm{Th}_{\mathrm{xs}}$ ratios and the production ratio of ${ }^{231} \mathrm{~Pa}$ and ${ }^{230} \mathrm{Th}$ in sea water. The residence time of sea water within the Arctic (120-360 yr) was calculated by dividing the Arctic basin volume $e^{41}\left(11.455 \times 10^{6} \mathrm{~km}^{3}\right)$ by the outflow through the Fram strait ${ }^{15}$ (1-3 Sv).

31. Choi, M. S. etal. Rapid determination of ${ }^{230} \mathrm{Th}$ and ${ }^{231} \mathrm{~Pa}$ in seawater by desolvated micro-nebulization inductively coupled plasma magnetic sector mass spectrometry. Mar. Chem. 76, 99-112 (2001).

32. Stuiver, M., Reimer, P. J. \& Reimer, R. W. CALIB Radiocarbon Calibration. http:// calib.qub.ac.uk/calib/ (version 5, 2005).

33. Hughen, K. A. et al. Marine04 marine radiocarbon age calibration, 26-0 ka BP. Radiocarbon 46, 1059-1086 (2004).

34. Fairbanks, R. G. et al. Marine radiocarbon calibration curve spanning 0 to 50,000 years B.P. based on paired ${ }^{230} \mathrm{Th} /{ }^{234} \mathrm{U} /{ }^{238} \mathrm{U}$ and ${ }^{14} \mathrm{C}$ dates on pristine corals. Quat Sci. Rev. 24, 1781-1796 (2005).

35. Poore, R. Z., Osterman, L., Curry, W. B. \& Phillips, R. L. Late Pleistocene and Holocene meltwater events in the western Arctic Ocean. Geology 27, 759-762 (1999).

36. Mangerud, J. \& Gulliksen, S. Apparent radiocarbon ages of recent marine shells from Norway, Spitsbergen, and Arctic Canada. Quat. Res. 5, 263-273 (1975).

37. Butzin, M., Prange, M. \& Lohmann, G. Radiocarbon simulations for the global ocean: the effects of wind stress, Southern Ocean sea ice and Heinrich events. Earth Planet. Sci. Lett. 235, 45-61 (2005)

38. Hanslik, D. et al. Quaternary Arctic Ocean sea ice variations and radiocarbon reservoir age corrections. Quat. Sci. Rev. 29, 3430-3441 (2010).

39. Mortlock, R. A. \& Froelich, P. N. A simple method for the rapid determination of biogenic opal in pelagic marine sediments. Deep Sea Res. A 36, 1415-1426 (1989).

40. Francois, R., Frank, M., Rutgers van der Loeff, M. M. \& Bacon, M. P. ${ }^{230}$ Th normalization: An essential tool for interpreting sedimentary fluxes during the late Quaternary. Paleoceanography 19, PA1018 (2004).

41. Jakobsson, M. Hypsometry and volume of the Arctic Ocean and its constituent seas. Geochem. Geophys. Geosyst. 3, http://dx.doi.org/10.1029/2001GC000302 (2002). 